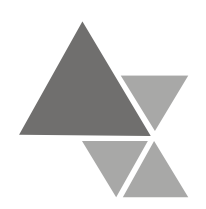

\title{
Participação dos Grupos de Alimentos no Valor Energético Total, nos Domicílios Rurais e Urbanos das Regiões Nordeste e Sudeste do Brasil
}

\author{
Daniela Cristina Rossetto Caroba ${ }^{1}$, Sonia Tucunduva Philippi ${ }^{2}$, Marina Vieira da Silva ${ }^{3}$
}

Este estudo teve por objetivo avaliar a participação relativa dos grupos de alimentos no Valor Energético Total (VET) para as famílias rurais e urbanas das Regiões Nordeste e Sudeste, de acordo com o rendimento mensal familiar. Foram utilizadas as informações da Pesquisa de Orçamentos Familiares (POF), realizada pelo Instituto Brasileiro de Geografia e Estatística (IBGE), entre julho de 2002 e junho de 2003. Os recursos do software Statistical Analysis System foram utilizados para as análises. Quanto à participação dos distintos grupos alimentares no VET, destaca-se a reduzida contribuição energética das frutas e hortaliças, bem como a elevada participação do grupo de açúcares e doces, evidenciadas para a totalidade das famílias analisadas. Foi notória a influência exercida pela localização dos domicílios, especialmente o estrato geográfico, bem como pelos rendimentos familiares, sobre a alimentação da população das Regiões Nordeste e Sudeste do Brasil.

Palavras-chave: consumo de alimentos, disponibilidade alimentar, domicílios rurais e urbanos, pesquisa de orçamento familiar, renda familiar.

\section{Food Group Contribution to the Total Energy Intake in Rural and Urban Domiciles from the Northeast and Southeast Regions of Brazil}

The objective of this paper was to evaluate the relative participation of the groups of foods in Total Energy Value (VET) for the rural and urban families in the Northeast and Southeast Regions, in accordance with the family's monthly income. For this purpose, the data from the Brazilian Institute of Geography and Statistics (IBGE), collected between July 2002 and June 2003 through the Family Budget Survey (POF), were used and subsequently processed by the Statistical Analysis System. Regarding the participation of the various food groups in the VET, the minute contribution of fruits and vegetables, compared to the strong participation of the group of sugars and candies to the Total Energy Value stood out, as evidenced by the totality of the families analyzed. The influence exerted by the location of the domiciles on the feeding pattern of the of the Brazilian northeastern and southeastern populations was notorious, especially when the geographic stratum and family income were combined.

Key-words: family budget survey, family income, food availability, food intake, rural and urban domiciles.

\footnotetext{
${ }^{1}$ PRONUT/USP

${ }^{2}$ Faculdade de Saúde Pública - USP

${ }^{3}$ ESALQ/USP
} 


\section{Introdução}

No Brasil, as informações sobre consumo alimentar da população, ainda hoje, são reduzidas. Ao mesmo tempo, são graves e flagrantes os problemas decorrentes da inadequação de consumo de alimentos, pois, nas últimas décadas, condições favoráveis à ocorrência de deficiências nutricionais têm sido gradativamente substituídas por epidemia de obesidade e doenças crônicas, relacionadas ao consumo excessivo e desequilibrado de alimentos. O padrão dietético associado à obesidade e a outras doenças crônicas é caracterizado, essencialmente, pelo consumo insuficiente de frutas e hortaliças e pelo consumo excessivo de alimentos de alta densidade energética e ricos em gorduras, açúcares e sal. Tal situação desenha um perfil epidemiológico complexo, que exige acompanhamento competente e minucioso, a fim de subsidiar políticas de intervenção. Como dificuldade adicional, as dimensões territoriais do país, do mesmo modo que sua diversidade regional, são fatores que dificultam a operacionalização de levantamentos ${ }^{[1,2]}$.

$\mathrm{O}$ conjunto de informações disponíveis, em meados da década de 90, revela que a população brasileira passou a consumir maior quantidade de alimentos de origem animal, enquanto cereais e leguminosas passaram a ser ingeridos em menor quantidade. Em algumas regiões do país, o consumo médio de gordura revelou-se superior à recomendação máxima $(30 \%$ da energia total). Nota-se também que a proporção de adultos obesos aumentou em mais de $50 \%$, a partir do início da década de $70^{[3]}$.

Segundo Pedraza ${ }^{[4]}$, a disponibilidade de alimentos é um requisito essencial para a segurança alimentar e o bem-estar nutricional da população. Depende da produção agropecuária, principalmente nos países em desenvolvimento e nas zonas rurais, pois está sujeita à produção para o consumo, visto que grande parte da população residente nessas regiões está vinculada a esta forma direta de obtenção de alimentos. A disponibilidade de alimentos é dependente, também, da redução de perdas pós-colheita, das políticas comerciais, do volume das importações (principalmente nos países desenvolvidos) e exportações, dos preços internacionais dos alimentos, entre outros fatores.

A avaliação do consumo alimentar de uma população, como o conhecimento da ingestão de energia e nutrientes, são ferramentas importantes para conhecer seu estado nutricional e viabilizar o planejamento de programas de intervenção de forma coerente e segundo suas necessidades, assim como para investigar as inter-relações do estado nutricional com o estado de saúde dessa população ${ }^{[5,6]}$.

A escolha dos alimentos, sua preparação e consumo estão relacionados com a identidade cultural, portanto, são fatores desenvolvidos ao longo do tempo, que distinguem um grupo social de outro e que estão intimamente relacionados com a história, o ambiente $\mathrm{e}$ as exigências específicas impostas ao grupo social pela vida do dia-adia. Assim, cada sociedade estabelece um conjunto de práticas alimentares, consolidadas ao longo do tempo. Estas práticas expressam diferentes culturas alimentares, algumas ligadas ao que é tradicional e outras ao que é inovador. Algumas não se fixam, desaparecendo pouco a pouco. Outras se enraízam, vindo a constituir hábitos alimentares e, em muitos casos, constituindose como verdadeiro patrimônio cultural ${ }^{[7]}$.

Segundo Martins ${ }^{[8]}$, nos aglomerados urbanos, a alimentação apresenta características distintas daquelas encontradas no meio rural. Enquanto nos centros urbanos o trabalho é normalmente sedentário, no meio rural há o envolvimento do esforço físico, exigindo uma alimentação compatível, com maior conteúdo de energia, líquidos, entre outros nutrientes. Destaca-se também o fato de 
que no meio rural a produção para $\mathrm{o}$ autoconsumo supre parte das necessidades alimentares, ao passo que nas áreas urbanas, a obtenção de alimentos envolve, predominantemente, transações comerciais.

Machado ${ }^{[9]}$ afirma que renda familiar e preços relativos são fortes determinantes da aquisição e das principais categorias dos alimentos. É indiscutível o fato que os alimentos constituem bens sujeitos às leis de mercado e que, portanto, renda e preços são fatores fundamentais à indicação da quantidade adquirida de cada bem. No entanto, dada uma restrição orçamentária, as escolhas no processo de aquisição são estabelecidas pela estrutura de preferências dos indivíduos.

Tendo em vista as dimensões geográficas e populacionais observadas no Brasil e diante das expressivas mudanças observadas nos padrões dietéticos da população, julgou-se relevante a realização deste trabalho, tendo por base as Regiões Nordeste e Sudeste do Brasil, pelo fato de apresentarem grande contingente populacional e serem distintas quanto ao índice de distribuição de renda, características culturais, de escolaridade e níveis de desenvolvimento econômico vigentes. Dessa forma, o objetivo deste artigo foi avaliar a participação relativa dos grupos de alimentos no Valor Energético Total (VET), disponíveis para as famílias moradoras nestas regiões brasileiras, de acordo com a localização do domicílio (rural ou urbano) e o rendimento mensal familiar.

\section{Material e Métodos}

\section{Base de Dados}

Foram utilizadas como base de dados as informações individuais obtidas pela Pesquisa de Orçamentos Familiares (POF), realizada pelo Instituto Brasileiro de Geografia e Estatística (IBGE). Os dados da amostra da pesquisa (total de 48.470 domicílios) foram coletados nas áreas urbanas e rurais, em todo o território brasileiro, durante o período de um ano, compreendido entre 01 de julho de $2002 \mathrm{e}$ 30 de junho de $2003^{[10]}$.

A POF visou mensurar as estruturas de consumo, dos gastos e dos rendimentos das famílias e possibilita traçar um perfil das condições de vida da população brasileira, a partir da análise de seus orçamentos domésticos. Além das informações referentes à estrutura orçamentária, várias características associadas às despesas e rendimentos dos domicílios e famílias foram investigadas, viabilizando o desenvolvimento de estudos sobre a composição dos gastos das famílias, segundo as classes de rendimentos, as disparidades regionais e nas áreas urbanas e rurais, a extensão do endividamento familiar, entre outras ${ }^{[11]}$.

As informações da Pesquisa de Orçamentos Familiares foram obtidas diretamente nos domicílios particulares permanentes selecionados, por meio de entrevistas junto aos seus moradores, durante um período de nove dias consecutivos. Para cada informação de quantidade de produtos alimentares adquirida e comunicada em campo, o valor anual foi obtido aplicando-se o multiplicador correspondente ao número de dias do ano dividido pelo número de dias pesquisados na Caderneta de Despesa Coletiva (sete), gerando-se um fator de anualização igual a 52, obtendo-se as quantidades de alimentos adquiridos em "quilogramas por ano".

Os produtos alimentares, cujas informações foram registradas na POF de 2002-2003, foram classificados segundo uma base cadastral pré-definida pelo IBGE. Ao final da pesquisa, esta base apresentou um total de 5.442 descrições de produtos alimentares, totalizando 1.680 tipos de alimentos e bebidas.

Quanto às informações relativas ao rendimento familiar, os dados foram apresentados por estrato de renda mensal familiar (expressa em salários mínimos -

\footnotetext{
${ }^{4}$ A data referencial fixada para apresentação dos resultados da POF 2002-2003 foi 15 de janeiro de 2003, em que o valor do salário mínimo correspondia a $\mathrm{R} \$ 200,00$.
} 
s.m. $)^{4}$, a saber: até 2,0 s.m., de 2,1 a 3,0 s.m., de 3,1 a 5,0 s.m., de 5,1 a 8,0 s.m., de 8,1 a 10,0 s.m., de 10,1 a 12,0 s.m., de 12,1 a 15,0 s.m., de 15,1 a 20,0 s.m., de 20,1 a 30,0 s.m. e mais de 30,0 s.m ${ }^{[12]}$.

\section{Construção do Banco de Dados}

Por meio dos microdados da POF 2002-2003 ${ }^{[10]}$, relativos à aquisição alimentar domiciliar per capita anual (em quilogramas) das famílias integrantes da amostra, foi realizado um agrupamento, considerando-se a totalidade dos alimentos que compunham o banco de dados original (cerca de 5.400 citações) e tendo por base a semelhança entre suas composições nutricionais.

Em seguida, os alimentos e suas respectivas quantidades foram cadastrados no software Virtual Nutri - Sistema de Análise Nutricional (versão 6.0), visando-se o cálculo do conteúdo de energia e nutrientes ${ }^{[13]}$. Partindo do cadastro de alimentos, foram construídas planilhas, por meio do software Microsoft Excel [14], referentes à disponibilidade alimentar, contendo o valor energético e os nutrientes de todos os produtos.

Todos os alimentos foram classificados, conforme critérios de semelhança quanto à composição nutricional, em dezessete grupos, a saber: cereais e derivados; raízes, tubérculos e derivados; carnes e embutidos; leguminosas; leite e derivados; ovos; hortaliças; frutas; açúcares e doces; óleos e gorduras vegetais; banha, toucinho, maionese e creme de leite; oleaginosas; refrigerantes; bebidas nãoalcoólicas; bebidas alcoólicas; preparações prontas para o consumo e condimentos.

Visando a obtenção da disponibilidade alimentar domiciliar per capita diária, efetuou-se a divisão dos valores de consumo anual de cada alimento em quilogramas, divulgados pelo IBGE na forma de microdados, por 365 dias, e os valores encontrados foram multiplicados por 1.000, com vistas à obtenção dos dados de consumo em gramas. A partir destes valores, foi calculada a participação dos grupos alimentares no VET das famílias moradoras nas áreas rurais e urbanas das Regiões Nordeste e Sudeste do Brasil, utilizando-se os recursos do software Statistical Analysis System ${ }^{[15]}$.

\section{Análise dos Dados}

Foram selecionados, para as análises, os dados relativos à população residente nas áreas rurais e urbanas das regiões Nordeste e Sudeste do Brasil.

A Região Nordeste inclui os estados de Alagoas, Bahia, Ceará, Maranhão, Paraíba, Pernambuco, Piauí, Rio Grande do Norte e Sergipe, ocupando uma área de 1.561.177,8 $\mathrm{km}^{2}$, o que corresponde a $18,26 \%$ da área total do País ${ }^{[16]}$. Sua população totaliza 47.741 .711 habitantes, o que representa $28,12 \%$ da população do país, sendo 32.975.425 habitantes na zona urbana $(69,07 \%)$ e 14.766.286 habitantes na zona rural $(30,93 \%)$. A expectativa de vida nessa região é a menor do país $(64,22$ anos). A densidade demográfica é de 30,69 habitantes por $\mathrm{km}^{2}$ e seu Índice de Desenvolvimento Humano (IDH) é de $0,685^{[17]}$.

Formada pelos Estados do Espírito Santo, Minas Gerais, Rio de Janeiro e São Paulo, a Região Sudeste ocupa 10,85\% do território brasileiro, com uma área de $927.286,2 \mathrm{~km}^{2}{ }^{[16]}$. É a região brasileira que apresenta a maior população, somando 72.412.411 habitantes, o que representa $42,65 \%$ da população do país, sendo 65.549.194 habitantes na zona urbana $(90,52 \%)$ e 6.863 .217 habitantes na zona rural $(9,48 \%)$. A expectativa de vida nessa região é de 67,53 anos e a densidade demográfica é de 72,26 habitantes por $\mathrm{km}^{2}$. Apresenta o mais alto índice de urbanização do país (88\%) e seu IDH é de $0,806^{[17]}$.

A contribuição relativa dos grupos, para a disponibilidade alimentar das famílias 
integrantes da amostra, foi expressa a partir da proporção percentual de energia que o alimento representava no total de energia (VET) disponível para consumo no âmbito domiciliar, considerando-se o estrato de renda e a situação geográfica do domicílio a que pertenciam.

Adotou-se como parâmetro para a avaliação da disponibilidade de energia, o valor de $2.000 \mathrm{kcal}$, recomendado pelo Guia Alimentar para a População Brasileira ${ }^{[18]}$. Vale ressaltar que este valor é uma estimativa da necessidade média para uma população considerada sedentária. Em média, os homens brasileiros alcançam o balanço energético com cerca de $2.400 \mathrm{kcal}$ por dia e as mulheres com, aproximadamente, 1.800 a $2.200 \mathrm{kcal}$ por dia. A média de $2.000 \mathrm{kcal}$ atende também às necessidades de energia das pessoas mais jovens.

Cabe registrar que a adoção dos valores de referência, preconizados para a população adulta, foi realizada partindo-se do pressuposto que, caso sejam atendidas as demandas dos adultos (jovens), a probabilidade de praticamente todos os membros das famílias (em distintos estágios de vida) terem o atendimento de suas necessidades nutricionais é garantida.

\section{Resultados}

Participação relativa dos grupos de alimentos na energia total disponível nos domicílios, de acordo com a região e localização do domicílio.

Na Tabela 1, é possível observar a participação relativa dos grupos de alimentos no VET diário disponível para as famílias das duas regiões brasileiras estudadas, de acordo com o estrato geográfico a que pertencem.

Os dados revelaram que as contribuições dos cereais, raízes/tubérculos e leguminosas, para o VET das famílias moradoras nas áreas rurais e urbanas da Região Nordeste, correspondem a $62,53 \%$ e $56,63 \%$, respectivamente. Com relação à Região Sudeste, observou-se que a contribuição desses alimentos para a energia total disponível alcança os valores de $55,44 \%$ entre as famílias rurais e $43,83 \%$ entre aquelas moradoras das áreas urbanas.

Quando se considerou a contribuição energética proveniente dos alimentos de origem animal (carne e embutidos, leite e derivados e ovos), observou-se que nos domicílios urbanos, das duas regiões analisadas, a disponibilidade é maior, sendo que para as famílias do Sudeste esse valor alcança $17,5 \%$ e para o Nordeste $14,06 \%$.

A contribuição para o VET de frutas e hortaliças foi de $2,17 \%$ e $1,21 \%$ para as famílias da Região Sudeste, residentes nas áreas urbanas e rurais, respectivamente. Com relação à Região Nordeste, os resultados apontaram uma maior participação desses alimentos no VET das famílias pertencentes às áreas urbanas $(1,96 \%$ contra $0,86 \%)$.

Foi possível observar que a participação do grupo de alimentos integrado pelos açúcares e doces e também pelo grupo dos refrigerantes supera o limite máximo de $10 \%$ preconizado ${ }^{[19]}$. A contribuição dos óleos e gorduras vegetais para o VET revelou-se maior para as famílias dos domicílios da Região Sudeste, considerando ambos estratos geográficos.

\section{Participação relativa dos grupos de alimentos na energia total disponível nos domicílios, de acordo com a região e rendimento mensal familiar.}

Nas Tabelas 2 e 3, são apresentados os resultados referentes à participação relativa dos grupos alimentares no VET diário disponível para as famílias brasileiras residentes nas Regiões Nordeste e Sudeste, de acordo com os rendimentos mensais familiares. 
Tabela 1 - Participação relativa dos grupos de alimentos no Valor Energético Total (VET) diário disponível para as famílias das Regiões Nordeste e Sudeste do Brasil, de acordo com o estrato geográfico (rural ou urbano), 2002/2003.

\begin{tabular}{l|rr|r|r}
\hline \multirow{2}{*}{\multicolumn{1}{c}{ Grupos de alimentos }} & \multicolumn{3}{c}{ Regiões e Estratos Geográficos } \\
\cline { 2 - 5 } & \multicolumn{2}{c}{ Nordeste } & \multicolumn{3}{c}{ Sudeste } \\
\cline { 2 - 5 } Cereais e derivados & Rural & Urbano & Rural & Urbano \\
Raízes, tubérculos e derivados & 37,08 & 38,54 & 42,85 & 36,28 \\
Carnes e embutidos & 14,59 & 8,67 & 2,95 & 2,44 \\
Leguminosas & 7,43 & 10,24 & 6,15 & 10,66 \\
Leite e derivados & 10,86 & 7,85 & 9,64 & 5,11 \\
Ovos & 2,84 & 3,33 & 5,31 & 6,82 \\
Hortaliças & 0,29 & 0,49 & 0,03 & 0,02 \\
Frutas & 0,27 & 0,51 & 0,31 & 0,51 \\
Açúcares e doces & 0,59 & 1,45 & 0,90 & 1,66 \\
Óleos e gorduras vegetais & 14,60 & 14,43 & 15,20 & 15,14 \\
Banha, toucinho, maionese e creme de leite & 9,74 & 10,91 & 12,32 & 14,66 \\
Oleaginosas & 0,74 & 1,17 & 2,68 & 2,00 \\
Refrigerantes & 0,02 & 0,01 & 0,00 & 0,02 \\
Bebidas não-alcoólicas & 0,25 & 0,79 & 0,56 & 1,61 \\
Bebidas alcoólicas & 0,22 & 0,36 & 0,34 & 0,57 \\
Preparações prontas para o consumo & 0,11 & 0,36 & 0,26 & 0,68 \\
Condimentos & 0,15 & 0,48 & 0,28 & 1,37 \\
Total & 0,22 & 0,41 & 0,22 & 0,45 \\
\hline
\end{tabular}

Examinando os dados reunidos nas Tabelas 2 e 3, verifica-se que, com relação ao grupo dos cereais e derivados, a maior contribuição observada na Região Sudeste $(41,88 \%)$ ocorre entre as famílias com rendimentos menores ou iguais a 2,00 s.m. No Nordeste, observam-se $39,97 \%$ de participação desse grupo nos domicílios com rendimentos familiares que variam de 2,1 a 3,0 s.m.

Os dados referentes às raízes, tubérculos e derivados evidenciam a existência de uma relação inversa entre a contribuição energética proveniente desse grupo e o recebimento mensal familiar identificado nos domicílios da Região Nordeste. Entre as famílias da Região Sudeste, a maior contribuição desse grupo $(3,00 \%)$ para a disponibilidade energética foi verificada entre aquelas com rendimentos que variam entre 5,1 e 6,0 s.m.
No tocante às carnes e embutidos e ao leite e derivados, nota-se que, nos domicílios da Região Nordeste, a contribuição desses grupos para a disponibilidade de energia da dieta é nitidamente crescente conforme ocorre aumento do rendimento familiar. No Sudeste, a maior contribuição do grupo das carnes e embutidos (12,43\%) foi observada nos familiares cujos rendimentos integram 0 intervalo de 15,1 a 20,0 s.m., enquanto para o grupo do leite e derivados, a participação revela-se mais expressiva $(10,16 \%)$ entre as famílias pertencentes ao segundo maior estrato de renda (20,1 a 30,0 s.m.).

Examinando-se os dados relativos às leguminosas, verifica-se que nos domicílios nordestinos mais pobres há maior participação $(10,23 \%)$ no VET, enquanto na Região Sudeste a participação mais expressiva $(7,76 \%)$ foi verificada nos domicílios cujas famílias dispunham de rendimentos que variavam entre 15,1 e 20,0 s.m. 
Tabela 2 - Participação dos grupos de alimentos no Valor Energético Total (VET) diário disponível nos domicílios da Região Nordeste do Brasil, de acordo com o rendimento mensal familiar, 2002/2003.

\begin{tabular}{|c|c|c|c|c|c|c|c|c|c|c|}
\hline \multirow{3}{*}{ Grupos de alimentos } & \multicolumn{10}{|c|}{ Região Nordeste } \\
\hline & \multicolumn{10}{|c|}{ Rendimento mensal familiar (em salários mínimos) } \\
\hline & $\leq 2,0$ & $2,1-3,0$ & $3,1-5,0$ & $5,1-6,0$ & $6,1-8,0$ & $\begin{array}{c}8,1- \\
10,0\end{array}$ & $\begin{array}{c}10,1- \\
15,0\end{array}$ & $\begin{array}{c}15,1- \\
20,0\end{array}$ & $\begin{array}{c}20,1- \\
30,0\end{array}$ & $\geq 30,1$ \\
\hline Cereais e derivados & 37,94 & 39,97 & 38,33 & 38,57 & 37,81 & 38,55 & 37,56 & 32,09 & 33,58 & 30,80 \\
\hline Raízes, tubérculos e derivados & 13,21 & 12,47 & 10,34 & 10,12 & 8,08 & 6,73 & 6,42 & 6,47 & 6,97 & 4,37 \\
\hline Carnes e embutidos & 7,73 & 8,21 & 9,29 & 10,10 & 11,19 & 11,32 & 11,62 & 11,30 & 12,85 & 13,42 \\
\hline Leguminosas & 10,23 & 9,21 & 8,99 & 8,24 & 7,92 & 6,98 & 6,29 & 8,16 & 4,89 & 7,57 \\
\hline Leite e derivados & 2,29 & 2,42 & 2,94 & 3,40 & 3,51 & 4,16 & 4,64 & 5,74 & 7,48 & 7,80 \\
\hline Ovos & 0,38 & 0,35 & 0,45 & 0,45 & 0,45 & 0,49 & 0,49 & 0,46 & 0,68 & 0,54 \\
\hline Hortaliças & 0,29 & 0,34 & 0,45 & 0,55 & 0,46 & 0,57 & 0,69 & 0,63 & 0,90 & 0,78 \\
\hline Frutas & 0,68 & 0,77 & 1,06 & 1,38 & 1,32 & 1,77 & 2,32 & 2,06 & 3,12 & 3,01 \\
\hline Açúcares e doces & 15,21 & 14,41 & 14,76 & 13,23 & 14,93 & 13,82 & 13,38 & 14,45 & 13,00 & 11,67 \\
\hline Óleos e gorduras vegetais & 10,25 & 9,90 & 10,56 & 10,90 & 10,98 & 11,11 & 11,32 & 12,46 & 9,36 & 11,60 \\
\hline Banha, toucinho, maionese e creme de leite & 0,65 & 0,70 & 0,99 & 0,90 & 0,99 & 1,44 & 2,04 & 2,30 & 2,31 & 2,95 \\
\hline Oleaginosas & 0,02 & 0,00 & 0,00 & 0,06 & 0,00 & 0,00 & 0,00 & 0,00 & 0,02 & 0,02 \\
\hline Refrigerantes & 0,31 & 0,42 & 0,57 & 0,65 & 0,77 & 1,01 & 1,06 & 1,41 & 1,85 & 1,60 \\
\hline Bebidas não-alcoólicas & 0,28 & 0,24 & 0,28 & 0,28 & 0,30 & 0,36 & 0,44 & 0,47 & 0,41 & 0,87 \\
\hline Bebidas alcoólicas & 0,12 & 0,12 & 0,32 & 0,33 & 0,37 & 0,50 & 0,55 & 0,56 & 0,85 & 0,83 \\
\hline Preparações prontas para o consumo & 0,19 & 0,20 & 0,35 & 0,48 & 0,45 & 0,67 & 0,65 & 0,77 & 1,09 & 1,23 \\
\hline Condimentos & 0,22 & 0,27 & 0,32 & 0,36 & 0,47 & 0,52 & 0,53 & 0,67 & 0,64 & 0,94 \\
\hline Total & 100,00 & 100,00 & 100,00 & 100,00 & 100,00 & 100,00 & 100,00 & 100,00 & 100,00 & 100,00 \\
\hline
\end{tabular}


Tabela 3 - Participação dos grupos de alimentos no Valor Energético Total (VET) diário disponível nos domicílios da Região Sudeste do Brasil, de acordo com o rendimento mensal familiar, 2002/2003.

\begin{tabular}{|c|c|c|c|c|c|c|c|c|c|c|}
\hline \multirow{3}{*}{ Grupos de alimentos } & \multicolumn{10}{|c|}{ Região Sudeste } \\
\hline & \multicolumn{10}{|c|}{ Rendimento mensal familiar (em salários mínimos) } \\
\hline & $\leq 2,0$ & $2,1-3,0$ & $3,1-5,0$ & $5,1-6,0$ & $6,1-8,0$ & $\begin{array}{c}8,1- \\
10,0\end{array}$ & $\begin{array}{c}10,1- \\
15,0\end{array}$ & $\begin{array}{c}15,1- \\
20,0\end{array}$ & $\begin{array}{c}20,1- \\
30,0\end{array}$ & $\geq 30,1$ \\
\hline Cereais e derivados & 41,88 & 39,50 & 41,75 & 38,44 & 37,69 & 35,41 & 35,61 & 32,48 & 32,71 & 30,95 \\
\hline Raízes, tubérculos e derivados & 2,86 & 2,83 & 2,30 & 3,00 & 2,38 & 2,47 & 2,29 & 2,63 & 2,22 & 2,59 \\
\hline Carnes e embutidos & 7,23 & 7,11 & 9,13 & 9,74 & 9,27 & 11,14 & 12,40 & 12,43 & 12,30 & 10,56 \\
\hline Leguminosas & 6,16 & 6,05 & 6,62 & 6,64 & 5,69 & 4,76 & 4,69 & 7,76 & 3,82 & 4,54 \\
\hline Leite e derivados & 4,26 & 5,00 & 5,49 & 5,62 & 6,35 & 6,00 & 7,57 & 7,49 & 10,16 & 9,63 \\
\hline Ovos & 0,03 & 0,02 & 0,03 & 0,02 & 0,02 & 0,02 & 0,02 & 0,02 & 0,02 & 0,02 \\
\hline Hortaliças & 0,36 & 0,45 & 0,40 & 0,45 & 0,45 & 0,44 & 0,52 & 0,57 & 0,66 & 0,64 \\
\hline Frutas & 0,91 & 0,88 & 1,06 & 1,12 & 1,51 & 1,55 & 1,99 & 1,88 & 2,58 & 2,58 \\
\hline Açúcares e doces & 17,06 & 18,44 & 16,01 & 14,22 & 15,76 & 15,59 & 12,94 & 14,41 & 12,23 & 13,99 \\
\hline Óleos e gorduras vegetais & 14,36 & 15,59 & 11,90 & 15,69 & 15,20 & 16,54 & 14,43 & 12,65 & 13,46 & 15,21 \\
\hline Banha, toucinho, maionese e creme de leite & 3,12 & 1,56 & 2,35 & 1,78 & 1,77 & 1,77 & 2,20 & 1,76 & 2,51 & 2,23 \\
\hline Oleaginosas & 0,00 & 0,00 & 0,00 & 0,00 & 0,02 & 0,00 & 0,04 & 0,00 & 0,07 & 0,04 \\
\hline Refrigerantes & 0,66 & 0,81 & 1,30 & 1,21 & 1,53 & 1,54 & 1,97 & 1,78 & 2,21 & 1,73 \\
\hline Bebidas não-alcoólicas & 0,31 & 0,40 & 0,38 & 0,42 & 0,49 & 0,54 & 0,70 & 0,64 & 0,85 & 0,78 \\
\hline Bebidas alcoólicas & 0,19 & 0,45 & 0,36 & 0,46 & 0,57 & 0,62 & 0,54 & 0,90 & 1,12 & 1,42 \\
\hline Preparações prontas para o consumo & 0,39 & 0,56 & 0,60 & 0,76 & 0,89 & 1,22 & 1,66 & 2,09 & 2,55 & 2,44 \\
\hline Condimentos & 0,23 & 0,35 & 0,32 & 0,43 & 0,41 & 0,39 & 0,43 & 0,50 & 0,53 & 0,65 \\
\hline Total & 100,00 & 100,00 & 100,00 & 100,00 & 100,00 & 100,00 & 100,00 & 100,00 & 100,00 & 100,00 \\
\hline
\end{tabular}


Analisando-se os dados referentes à contribuição do grupo das hortaliças e do grupo das frutas, pode-se observar que os maiores valores identificados ocorrem entre as famílias pertencentes às duas maiores classes de renda, de ambas as regiões brasileiras analisadas.

Nota-se que a contribuição mais expressiva $(18,44 \%)$ dos açúcares e doces foi identificada nos domicílios das famílias moradoras na Região Sudeste com rendimentos entre 2,1 e 3,0 s.m., enquanto que a menor participação desse grupo de alimentos $(11,67 \%)$ foi verificada entre as famílias mais ricas ( $\geq 30,1$ s.m.) da Região Nordeste.

Entre as famílias da Região Sudeste ocorreu a mais expressiva participação no VET dos óleos e gorduras vegetais e do grupo da banha, toucinho, maionese e creme de leite. Nos domicílios com rendimentos entre 8,1 e 10,0 s.m., a proporção de óleos e gorduras vegetais chega a $16,54 \%$, e entre as famílias mais pobres $(\leq 2,0$ s.m. $)$, o grupo de alimentos considerados fontes de gorduras saturadas (banha, toucinho, maionese e creme de leite) revelou participação de $3,12 \%$.

\section{Discussão}

Análise da participação relativa dos grupos de alimentos na energia total disponível nos domicílios, de acordo com a região e localização do domicílio.

A participação relativa dos grupos de alimentos foi analisada tendo por base o cálculo da proporção de energia oriunda dos distintos grupos no conteúdo total de energia disponível para o consumo, no âmbito dos domicílios.

É importante observar que a participação do grupo das raízes, tubérculos e derivados (Tabela 1) foi cerca de cinco vezes superior para os moradores da zona rural do Nordeste (14,59\%), comparada à mesma área (rural) do Sudeste $(2,95 \%)$. Do mesmo modo, quando foram analisados os resultados relativos às famílias residentes nas áreas urbanas de ambas as regiões, constatou-se que a participação desse grupo se mostrou 3,5 vezes superior para os moradores da Região Nordeste $(8,67 \%$ no VET versus $2,44 \%)$.

Conforme informações do Guia Alimentar para a População Brasileira ${ }^{[18]}$, a alimentação diária deve conter seis porções provenientes do grupo de cereais, raízes, tubérculos e derivados. Isso equivale a cerca de $900 \mathrm{kcal}$ ou cerca de $45 \%$ de contribuição desse grupo para o valor energético total, quando se considera uma dieta de $2.000 \mathrm{kcal}$. Para as leguminosas essa recomendação é de uma porção diária $(55 \mathrm{kcal}$ ou $2,75 \%$ de contribuição no VET).

Dessa forma, verificou-se que apenas para as famílias urbanas da Região Sudeste a recomendação de participação do grupo dos cereais, raízes, tubérculos e derivados não era atendida $(38,72 \%)$. Com relação à contribuição energética das leguminosas, em todos os domicílios das duas regiões brasileiras, as necessidades nutricionais foram satisfeitas.

A participação dos ovos no VET disponível para as famílias nordestinas foi superior, tanto para aquelas residentes na área rural $(0,29 \%)$ quanto para as moradoras da área urbana $(0,49 \%)$, em relação àqueles grupamentos da Região Sudeste (perto de 9,7 e 24,5 vezes maior nos estratos rural e urbano, respectivamente).

De acordo com o Guia Alimentar para a População Brasileira ${ }^{[18]}$, a recomendação calórica média do grupo das carnes e ovos é de $190 \mathrm{kcal}$ (1 porção diária), que corresponde a cerca de $9,5 \%$ da energia total da dieta $(2.000$ kcal). Para o grupo do leite e derivados, recomenda-se o consumo de 3 porções diárias (360 kcal), o que equivale a, aproximadamente, $18 \%$ do VET.

Notou-se que, nos domicílios urbanos de ambas as regiões brasileiras analisadas, a contribuição dos grupos das carnes e dos ovos mostra-se conforme as recomendações estabelecidas $(10,73 \%$ no Nordeste e $10,68 \%$ no Sudeste). Quanto à participação do grupo do leite e derivados no VET, é importante registrar que, para todas as famílias pesquisadas, os valores encontrados apresentam-se inferiores ao recomendado para a população brasileira. 
É interessante ressaltar que, no caso do leite e derivados, a contribuição foi cerca de 52,0\% superior para o VET disponível para as famílias residentes nas áreas urbanas da Região Sudeste $(6,82 \%)$, quando comparada à proporção obtida para as famílias nordestinas do mesmo estrato geográfico $(3,33 \%)$.

O leite é a melhor fonte de cálcio na alimentação. No Brasil, há uma aparente tendência de redução no consumo de leite pela população. Isso é particularmente preocupante quando se observa que as crianças e jovens vêm substituindo o consumo de leite por refrigerantes. Essa tendência repercute de forma negativa sobre a saúde óssea, pois a disponibilidade adequada de cálcio nas fases de crescimento e desenvolvimento pode ser comprometida e, também, as substâncias contidas no refrigerante impedem a fixação do cálcio na matriz óssea ${ }^{[18]}$.

Com relação a frutas e hortaliças, a participação no VET foi de 2,17\% e $1,21 \%$ para as famílias da Região Sudeste, residentes nas áreas urbanas e rurais, respectivamente. Para a Região Nordeste, os resultados apontaram uma maior contribuição desses alimentos para o VET disponível para as famílias moradoras da área urbana $(1,96 \%) \mathrm{em}$ relação àquelas residentes na área rural $(0,86 \%)$.

Para alcançar o consumo recomendado como saudável ${ }^{[18]}$ para esses grupos de alimentos (quantidade mínima de $400 \mathrm{~g} /$ dia per capita, que equivale à proporção de 9 a $12 \%$ do VET, considerando uma dieta de $2.000 \mathrm{kcal}$ ), é preciso aumentar em $4,15 \mathrm{e}$ em 7,4 vezes o consumo médio atual da população da Região Sudeste, residente nas áreas urbanas e rurais, respectivamente. A fim de alcançar a recomendação, para a população do Nordeste, as proporções de frutas e hortaliças disponíveis deveriam ser ampliadas em, aproximadamente, 4,6 vezes nos domicílios urbanos e 10,5 vezes naqueles localizados na zona rural.

O consumo insuficiente de frutas e hortaliças aumenta o risco de doenças crônicas não-transmissíveis, como as cardiovasculares e alguns tipos de câncer, e está entre os 10 fatores de risco que mais causam mortes e doenças em todo o mundo ${ }^{[20]}$.
O Brasil é um dos maiores produtores de frutas e hortaliças, produzindo principalmente frutas tropicais para exportação, e constitui um dos maiores importadores mundiais de frutas como maçãs, pêras, uvas e ameixas. No cenário mundial, semelhante à situação nacional, poucos países caracterizam-se por substancial consumo individual diário de frutas e hortaliças na dieta [21].

Levy-Costa e colaboradores (2005) ${ }^{[22]}$, em estudo sobre a distribuição e evolução da disponibilidade domiciliar de alimentos no Brasil, entre os anos de 1974 e 2003, verificaram que frutas e hortaliças correspondem a apenas $2,3 \%$ das calorias totais da dieta.

Com base nas informações coletadas na Pesquisa Mundial de Saúde, realizada pela Organização Mundial da Saúde em parceria com a Fundação Oswaldo Cruz, Jaime e Monteiro (2005) ${ }^{[23]}$ estimaram a frequiência e a distribuição do consumo de frutas e hortaliças entre a população brasileira, verificando que menos da metade $(41,0 \%)$ dos indivíduos adultos consumia frutas diariamente e menos de um terço da população $(30,0 \%)$ relatou o consumo diário de hortaliças. O consumo de frutas e hortaliças é maior nas áreas urbanas do que nas áreas rurais e aumenta com a idade e escolaridade dos indivíduos.

A participação no VET do grupo de alimentos integrado pelos açúcares e doces e também pelo grupo dos refrigerantes pode ser considerada elevada para a totalidade das famílias pesquisadas. Foi possível verificar que a situação mais desfavorável ocorre entre as famílias da área urbana da Região Sudeste. A contribuição dos referidos alimentos para o VET alcança $16,75 \%$. Os valores encontrados para as famílias nordestinas também podem ser considerados elevados (em média 15,0\%). A situação pode ser ainda mais desfavorável se forem considerados os alimentos consumidos fora do domicílio.

A Organização Mundial da Saúde [19] recomenda que o consumo de açúcares simples não deve ultrapassar $10 \%$ da energia total diária. O Guia Alimentar para a População Brasileira ${ }^{[18]}$ preconiza apenas uma 
porção diária do grupo dos açúcares e doces, equivalente a $110 \mathrm{kcal}$. Para uma dieta de $2.000 \mathrm{kcal}$, somente $5,5 \%$ da energia deve ser oriunda dos açúcares e doce. Dessa forma, verificou-se que a proporção média desse grupo no VET das famílias do Nordeste e Sudeste é cerca de 3 vezes superior ao recomendado.

Enes (2005) [24] observou uma disponibilidade (média) excessiva dos grupos dos açúcares e doces e dos refrigerantes para as famílias das regiões Norte e Sul do Brasil. A situação mais crítica correspondeu à realidade vivenciada pelas famílias da área urbana da Região Sul (15,1\%) e nos domicílios rurais da Região Norte tais valores corresponderam a 10,8\% de participação.

A participação de alimentos essencialmente calóricos (óleos e gorduras vegetais) na alimentação revela-se maior para as famílias dos domicílios da Região Sudeste, considerando ambos os estratos geográficos. $\mathrm{Na}$ área urbana, essa participação é de 14,66\% e na área rural alcança $12,32 \%$. Na Região Nordeste, a energia proveniente dos óleos e gorduras vegetais representa $9,74 \%$ e $10,91 \%$ do VET disponível para as famílias das áreas rurais e urbanas, respectivamente.

Levy-Costa e colaboradores (2005) ${ }^{[22]}$, estudando a distribuição e evolução da disponibilidade domiciliar de alimentos no Brasil, entre os anos de 1974 e 2003, verificaram aumento da participação relativa do grupo dos óleos e gorduras vegetais na dieta dos brasileiros, passando de 11,6\% em 1975 para 13,5\% em 2003.

A recomendação do Guia Alimentar para a População Brasileira ${ }^{[18]}$ para óleos, gorduras e sementes oleaginosas é de apenas uma porção diária, equivalente a $73 \mathrm{kcal}$. Para uma dieta de $2.000 \mathrm{kcal}$, somente $3,65 \%$ da energia deve originar desse grupo. Nesta pesquisa, pode-se verificar que a proporção média $(11,73 \%)$ do grupo dos óleos e gorduras vegetais no VET das famílias do Nordeste e Sudeste supera o preconizado para atender às necessidades de um adulto. Com relação às oleaginosas, os valores encontrados para a totalidade das famílias são reduzidos, chegando a ser nulo nos grupamentos rurais do Sudeste.
O grupo de alimentos composto por banha, toucinho, maionese e creme de leite apresenta contribuição mais expressiva $(2,68 \%)$ entre as famílias moradoras das áreas rurais da Região Sudeste. A referida proporção é, aproximadamente, 3,6 vezes superior à encontrada para os domicílios rurais da Região Nordeste. A participação desse grupo alimentar para o VET das famílias urbanas do Sudeste também é superior $(2,00 \%)$, quando comparada aos domicílios urbanos do Nordeste $(1,17 \%)$.

É provável que alimentos como maionese e creme de leite estão mais disponíveis entre as famílias urbanas, devido ao hábito alimentar voltado ao consumo de produtos industrializados, geralmente observado nessa população. $\mathrm{O}$ consumo excessivo de alimentos com elevado teor de gordura está associado ao aumento do risco de incidência de várias doenças. Devido à densidade energética da gordura, quando a dieta de populações sedentárias contém mais de $25 \%$ de gordura, as pessoas tendem a apresentar excesso de peso ou obesidade ${ }^{[18]}$.

Para as famílias urbanas do Sudeste, a participação de bebidas alcoólicas $(0,68 \%)$, bebidas não-alcoólicas $(0,57 \%)$, preparações prontas para o consumo $(1,37 \%)$ e condimentos $(0,45 \%)$ é superior, quando comparada aos demais grupamentos familiares.

Segundo dados da Associação Brasileira de Bebidas ${ }^{[25]}$, o abuso do álcool afeta cerca de $10 \%$ da população brasileira e o mercado de bebidas comercializa cerca de vinte categorias principais, com destaque para produção de cerveja $(88,8 \%)$, cachaça $(6,6 \%)$ e outras, como vinho, uísque e vodca $(4,6 \%)$. $\mathrm{O}$ consumo regular de álcool na quantidade de, pelo menos, três a quatro doses por dia ou mais, aumenta o risco de hipertensão e acidente vascular cerebral, de câncer de boca, garganta, esôfago e cólon e também o risco de câncer no fígado como conseqüência da cirrose hepática $^{[18]}$. 
Análise da participação relativa dos grupos de alimentos na energia total disponível nos domicílios, de acordo com a região e rendimento mensal familiar.

O grupo dos cereais e derivados revela participações mais expressivas $(41,88 \%$ e $41,75 \%$ ) entre as famílias da Região Sudeste, cujos rendimentos são inferiores ou iguais a 2,0 s.m. e entre aquelas que recebem entre 3,1 e 5,0 s.m. (Tabela 3). Na Região Nordeste, a maior contribuição $(39,97 \%)$ desse grupo de alimentos ocorre para os grupamentos familiares pertencentes ao segundo menor estrato de recebimento ( 2,1 a 3,0 s.m.). Entre as famílias mais ricas ( $\geq 30,1$ s.m.) de ambas as regiões foi identificada a menor contribuição desse grupo de alimentos para o VET disponível $(30,80 \%$ no Nordeste e $30,95 \%$ no Sudeste).

Os pães, o arroz e o milho são exemplos de alimentos que compõem o grupo de cereais e que integram o hábito alimentar brasileiro. Além de ricos em carboidratos complexos, são compostos por proteínas, vitaminas do complexo $\mathrm{B}$, minerais, ácidos graxos essenciais e fibras alimentares, nutrientes importantes para uma alimentação saudável. Além disso, apresentam baixo custo e possibilitam várias formas de utilização na $\operatorname{dieta}^{[26]}$.

As tendências observadas referentes à alimentação das pessoas de baixa renda são: proporção maior de gasto com alimentos no orçamento familiar, maior suscetibilidade às variações de preço, falta de acesso à informação sobre alimentação saudável, consumo no domicílio, dieta monótona e pobre, com pouca diversidade. Estudo realizado em Maceió (AL) mostrou que as preparações mais comuns, elaboradas nos domicílios mais pobres, incluíam alimentos como arroz, feijão, cuscuz, macarrão, pão e biscoito ${ }^{[27]}$.

Na Região Nordeste (Tabela 2), podese observar uma relação inversa entre a contribuição energética proveniente das raízes, tubérculos e derivados e o recebimento mensal familiar. Verifica-se ainda que a participação das raízes, tubérculos e derivados no VET, para as famílias nordestinas pertencentes ao estrato de menor rendimento $(13,21 \%)$, é cerca de três vezes maior, quando comparada àquela observada $(4,37 \%)$ para o grupamento mais rico. Pode-se supor que isso decorre do fato de serem produtos que apresentam menor preço, bem como derivados da produção para o autoconsumo. Entre as famílias da Região Sudeste, a maior contribuição desse grupo $(3,00 \%)$ na disponibilidade energética foi verificada entre as famílias com rendimentos que variam de 5,1 a 6,0 s.m., valor $70,4 \%$ menor que o observado entre as famílias do Nordeste, pertencentes ao mesmo estrato de rendimento $(10,12 \%)$.

No tocante aos grupos das carnes e embutidos e do leite e derivados, nota-se que, nos domicílios da Região Nordeste (Tabela 2), a contribuição desses grupos para a disponibilidade de energia da dieta é nitidamente maior conforme ocorre o crescimento dos rendimentos familiares. As famílias mais pobres dispõem na dieta de $7,73 \%$ da energia proveniente das carnes e embutidos e de $2,29 \%$ oriundos do grupo do leite e derivados. Nos grupamentos mais ricos, esses valores correspondem a $13,42 \%$ e $7,80 \%$, respectivamente.

Na Região Sudeste, a situação não é semelhante, havendo oscilações na participação desses grupos alimentares conforme há variação dos rendimentos familiares. Todavia, deve-se registrar que a maior participação do grupo das carnes e embutidos $(12,43 \%)$ no VET foi verificada entre as famílias da região cujos rendimentos encontram-se entre 15,1 e 20,0 s.m., contra $7,11 \%$ que recebem entre 2,1 e 3,0 salários mínimos.

Ainda no Sudeste, a contribuição menos expressiva de leite e derivados $(4,26 \%)$ foi encontrada entre as famílias mais pobres e atinge cerca de $42 \%$ da maior contribuição média verificada $(10,16 \%)$ entre os grupos moradores na região (rendimentos entre 20,1 e 30,0 s.m.).

Bleil ${ }^{[28]}$ verificou também que, entre as famílias residentes nas regiões metropolitanas de Curitiba e Porto Alegre, a participação do grupo de leite e derivados mostrou-se maior conforme aumentavam os rendimentos. Comparando concomitantemente 
os dados de ambas as regiões, Porto Alegre apresentou maior disponibilidade dos referidos grupos.

É interessante destacar que a contribuição energética proveniente do grupo do leite e derivados foi mais expressiva no VET das famílias da Região Sudeste. Faganello ${ }^{[29]}$ também observou, ao analisar dados obtidos em meados da década de 90, que a contribuição energética do leite e derivados no VET foi maior para a região mais rica (Sudeste), quando comparada com os dados da região considerada mais pobre (Nordeste).

Menezes e colaboradores [30] mostraram que as elasticidades-renda do leite e de seus derivados (queijos, iogurtes, requeijão, entre outros) são relativamente elevadas, indicando que o aumento da renda interfere positivamente na aquisição desses alimentos.

Verifica-se que as leguminosas tiveram maior participação $(10,23 \%)$ no VET das famílias nordestinas mais pobres (Tabela 2). Nos domicílios dessa região, que pertencem ao segundo maior estrato de renda (20,1 a 30,0 s.m.), observa-se a contribuição menos expressiva $(4,89 \%)$ desse grupo de alimentos. Nos grupamentos familiares do Sudeste, cujos rendimentos variam entre 15,1 e 20,0 s.m., pode-se notar que $7,76 \%$ da energia total da dieta era proveniente de leguminosas (Tabela 3).

Enes [24], examinando os dados relativos às leguminosas, verificou que, para as famílias da Região Sul, havia uma relação inversa entre a renda familiar e a participação desse grupo no VET disponível nos domicílios. Segundo o autor, tal resultado sugere que o consumo de arroz e feijão, hábito característico da população brasileira, é menos frequiente entre as famílias relativamente mais ricas.

De acordo com Hoffmann ${ }^{[31]}$, o consumo do feijão teve uma redução significativa, ao longo de duas décadas, principalmente nas regiões urbanizadas. A queda no consumo do feijão pode estar associada com a crescente participação da mulher no mercado de trabalho, uma vez que o tempo dedicado ao preparo deste alimento é grande e com isso, as mulheres, ainda majoritariamente responsáveis pelo preparo de alimentos nos domicílios brasileiros, acabam optando por alternativas mais simples para sua preparação e consumo ${ }^{[32]}$.

Analisando-se os dados referentes à contribuição do grupo das hortaliças para o VET, pode-se registrar que entre as famílias com rendimentos entre 20,1 e 30,0 s.m., de ambas as regiões analisadas, foram observadas as maiores proporções desses alimentos na energia disponível $(0,90 \%$ no Nordeste e $0,66 \%$ no Sudeste). Verifica-se entre as famílias mais pobres, tanto do Nordeste quanto do Sudeste, as menores contribuições energéticas oriundas das hortaliças folhosas $(0,29 \%)$ e das hortaliças frutosas $(0,36 \%)$.

Comparando-se os resultados relativos às famílias mais pobres $(\leq 2,0$ s.m. $)$ com aquelas com maiores rendimentos ( $\geq 30,1 \mathrm{s.m}$.) de ambas as regiões, observa-se que a contribuição das frutas para o VET revela-se superior nos domicílios das famílias mais ricas. Entre os grupamentos familiares mais ricos do Nordeste, essa participação $(3,01 \%)$ é cerca de 4,4 vezes maior em relação ao grupamento com os menores rendimentos $(0,68 \%)$. No Sudeste, essa diferença é de 2,8 vezes entre as famílias mais ricas $(2,58 \%)$ e aquelas com os menores rendimentos $(0,91 \%)$.

É importante ressaltar que a contribuição proveniente de hortaliças e frutas para a energia total da dieta, de todas as famílias analisadas, revela valores reduzidos, que não atendem à recomendação do Guia Alimentar para a População Brasileira ( 9 a $12 \%$ do VET) ${ }^{[18]}$.

De forma geral, o consumo de frutas e hortaliças no Brasil é tradicionalmente reduzido. A participação desses grupos no valor energético da alimentação das famílias brasileiras variou entre 3\% e $4 \%$ do VET, entre 1974 e 2003. Embora a tendência de consumo esteja relativamente estável, é preciso implementar esforços para que a população aumente bastante o consumo desses grupos de alimentos. Nem mesmo as famílias de maior renda consomem hoje o valor mínimo recomendado ${ }^{[18]}$.

Jaime e colaboradores ${ }^{[20]}$ estimam que o consumo de frutas e hortaliças no Brasil 
corresponda a menos da metade das recomendações nutricionais, sendo ainda mais deficiente entre as famílias de baixa renda. Segundo os referidos autores, não existem estudos brasileiros sobre esse consumo, mas pesquisa realizada em outros países em desenvolvimento destaca entre os fatores limitantes do baixo consumo de frutas e hortaliças: preços elevados (diante dos demais alimentos e em comparação com a renda das famílias), sistemas ineficientes de produção, distribuição e comercialização e desconhecimento da população sobre a importância daqueles alimentos para a saúde, sobretudo com relação a hortaliças.

Deve-se enfatizar a importância de programas nacionais que valorizem a produção e incentivem o consumo de alimentos regionais, ricos em fibras, vitaminas e minerais, colaborando para a economia local e para a qualidade de vida da população.

O grupo dos açúcares e doces apresentou participação expressiva para todos os grupamentos familiares analisados. A maioria das contribuições foi observada nos domicílios da Região Sudeste e o maior valor $(18,44 \%)$ ocorreu entre as famílias com rendimentos entre 2,1 e 3,0 s.m. dessa região. A menor participação $(11,67 \%)$ desse grupo foi verificada entre as famílias do Sudeste pertencentes ao segundo maior estrato de renda (20,1 a 30,0 s.m.).

Na Região Nordeste, a contribuição mais expressiva $(15,21 \%)$ de açúcares e doces foi identificada entre as famílias mais pobres ( $\leq 2,0$ s.m.), enquanto entre os mais ricos ( $\geq$ 30,1 s.m.) foi verificado o menor conteúdo disponível $(11,67 \%)$.

É interessante destacar que, nos domicílios mais pobres de ambas as regiões brasileiras, o grupo dos açúcares e doces é o que revela a segunda maior participação na energia total, atrás dos cereais e derivados.

Os açúcares simples, fontes apenas de energia, devem compor a alimentação em quantidades reduzidas, pois o seu consumo excessivo está diretamente relacionado com o aumento do risco da obesidade e outras doenças crônicas não-transmissíveis ${ }^{[18]}$.

A contribuição dos refrigerantes para a energia disponível nos domicílios é superior em todas as classes de renda da Região Sudeste, quando comparada às famílias da Região Nordeste. A maior proporção $(2,21 \%)$ desse grupo de alimentos, no VET disponível nos domicílios, foi verificada entre as famílias do Sudeste que possuem rendimentos entre 20,1 e 30,0 s.m., enquanto a participação menos expressiva $(0,31 \%)$ ocorreu entre as famílias mais pobres do Nordeste.

Os dados da POF 2002-2003 revelaram que, no período de 1974 a 2003, a quantidade anual per capita adquirida de refrigerante (para consumo no domicílio) aumentou de 1,3 litros para 7,7 litros, representando um crescimento de $490 \%{ }^{[11]}$. Supõe-se que esse fato é decorrente do aumento da produção e, consequientemente, da maior oferta do produto, como também se deve à diminuição do seu preço, além da mudança do hábito alimentar da população ao consumir a bebida.

$\mathrm{Na}$ Região Nordeste, a maior proporção referente ao grupo dos óleos e gorduras vegetais $(12,46 \%)$ foi identificada nos grupamentos familiares cujos rendimentos variam de 15,1 a 20,0 s.m. Entre as famílias mais ricas dessa região, foi observada a contribuição mais expressiva $(2,95 \%)$ do grupo da banha, toucinho, maionese e creme de leite.

Uma vez que os resultados da presente pesquisa não incluem o consumo de alimentos fora do domicílio, o que pode subestimar o consumo de alimentos altamente calóricos, julga-se necessária a orientação nutricional à da população sobre o comedimento no consumo de gorduras e alimentos com alta concentração energética, bem como sobre os tipos de gordura e seus efeitos sobre a saúde, visando adotar uma alimentação saudável.

\section{Conclusões}

Os resultados do presente trabalho revelam distintos comportamentos no tocante à disponibilidade alimentar para as famílias das Regiões Nordeste e Sudeste do Brasil. Há uma clara influência exercida por algumas variáveis, como a localização dos domicílios (especialmente o estrato geográfico) e os 
rendimentos familiares, sobre a alimentação da população das duas regiões brasileiras analisadas.

Características negativas dos padrões de consumo alimentar, evidenciadas para a totalidade das famílias integrantes da amostra desta pesquisa, referem-se à reduzida contribuição energética proveniente das frutas e hortaliças, não atingindo a recomendação para um indivíduo adulto.

Os valores obtidos, quanto à contribuição do grupo de açúcares e doces na energia total da dieta, despertam preocupação, pelo fato de excederem o percentual preconizado para a totalidade dos indivíduos integrantes das famílias. Os resultados devem ser examinados com atenção, pois o consumo elevado desses alimentos relaciona-se fortemente ao aumento do risco de obesidade, de doenças crônicas não-transmissíveis e de cáries dentárias.

\section{Referências Bibliográficas}

1- Galeazzi MAM, Domene SMA, Sichieri R. Estudo multicêntrico de consumo familiar NEPA/MS. Cad Debate. 1997, Ed Especial. 57

p.

2- Claro RM, Carmo HCE, Machado FMS, Monteiro CA. Renda, preço dos alimentos e participação de frutas e hortaliças na dieta. Rev. Saúde Pública. 2007;41(4):557-564.

3- Mondini L, Monteiro CA. Mudanças no padrão de alimentação da população urbana brasileira: 1962-1988. Rev. Saúde Pública. 1994; 28(6):433-439.

4- Pedraza DF. Disponibilidad de alimentos como factor determinante de la Seguridad Alimentaria y Nutricional y sus representaciones em Brasil. Rev. Nutr. 2005; 18(1):129-143.

5- Serra Majem LI. Evaluación del consume de alimentos en poblaciones: encuestas alimentarias. In: Serra Majem LI, Aranceta Bartrina J, Mataix Verdú J. Nutrición y salud publica: metodos, bases cientificas $y$ aplicaciones. Barcelona: Masson; 1995. p. 9096.

6- West CE, Van Staveren WA. Food consumption, nutrient intake and the use of food composition tables. In: Margetts BM, Nelson M. Design concepts in nutritional epidemiology. Oxford: Oxford University Press; 1997. p. 107-122.

7- Conselho Nacional de Segurança Alimentar e Nutricional - CONSEA. Princípios e Diretrizes de uma Política de Segurança Alimentar e Nutricional - Textos de Referência da II Conferência Nacional de Segurança Alimentar e Nutricional. Brasília, DF; 2004.

8- Martins E. Variações no consumo de alimentos no Brasil de 1974/75 a 1987/88. [dissertação de mestrado]. Piracicaba: Escola Superior de Agricultura "Luiz de Queiroz" da USP; 1998. 117 p.

9- Machado FMS. Estratégias de concorrência da indústria alimentícia e seus desdobramentos na dimensão nutricional. [tese de doutorado]. São Paulo: Faculdade de Ciências Farmacêuticas, Faculdade de Economia, Administração e Contabilidade, e Faculdade de Saúde Pública da USP; 2003. $200 \mathrm{p}$.

10- Instituto Brasileiro de Geografia e Estatística - IBGE. Pesquisa de Orçamentos Familiares 2002/2003: microdados - segunda divulgação. Rio de Janeiro, RJ; 2005.

11- Instituto Brasileiro de Geografia e Estatística - IBGE. Pesquisa de orçamentos familiares 2002-2003: primeiros resultados Brasil e grandes regiões. Rio de Janeiro, RJ; 2004a.

12- Instituto Brasileiro de Geografia e Estatística - IBGE. Pesquisa de orçamentos familiares 2002-2003: análise da disponibilidade domiciliar de alimentos e do estado nutricional no Brasil. Rio de Janeiro, RJ; 2004b.

13- Philippi ST, Szarfarc SC, Latterza AR. Virtual Nutri [software]. Versão 1.0. Universidade de São Paulo, Faculdade de Saúde Pública, Departamento de Nutrição, 1996.

14- Microsoft. Microsoft Excel 2000 [software], 2000.

15- The SAS System, version 8. [software em CD-ROM]. Cary: SAS Institute; 1998.

16- Brasil. Ministério das Relações Exteriores [homepage na internet]. Brasília; 2006. 
[acesso em 01 junho 2006]. Disponível em: http://www.mre.gov.br/

17- Muninet. Rede Brasileira para o Desenvolvimento Municipal. São Paulo; 2006. [acesso em 10 dezembro 2006]. Disponível em: http://muninet.org.br/

18- Brasil. Ministério da Saúde. Secretaria de Atenção à Saúde. Departamento de Atenção Básica. Coordenação-Geral da Política de Alimentação e Nutrição. Guia alimentar para a população brasileira: promovendo a alimentação saudável. Brasília, DF; 2006 b.

19- World Health Organization. Diet, nutrition and the prevention of chronic diseases. Geneva, 2003. (Technical Report Series, 916). 20- Jaime PC, Machado FMS, Westphal MF, Monteiro CA. Educação nutricional e consumo de frutas e hortaliças: ensaio comunitário controlado. Rev. Saúde Pública. 2007;41(1):154-157.

21- Machado FMS, Santiago VR. O papel das frutas e hortaliças na nutrição humana. In: Torres EAFS. Alimentos em questão: uma abordagem para as dúvidas mais comuns. São Paulo: Ponto Crítico; 2001.

22- Levy-Costa RB, Sichieri R, Pontes NS, Monteiro CA. Disponibilidade domiciliar de alimentos no Brasil: distribuição e evolução (1974-2003). Rev. Saúde Pública, 2005; 39(4):530-540.

23- Jaime PC, Monteiro CA. Fruit and intake by Brazilian adults. Cad. Saúde Pública, 2005; 21:S19-S24, Supl. 1.

24- Enes CC. Disponibilidade de energia e nutrientes nos domicílios: o contraste entre Regiões Norte e Sul do Brasil. [dissertação de mestrado]. Piracicaba: Escola Superior de
Agricultura "Luiz de Queiroz" da USP; 2005. $119 \mathrm{p}$.

25- Associação Brasileira de Bebidas. [Acesso em 2006 out 11]. Disponível em: <http://www.abrabe.org.br>.

26- Philippi ST. Nutrição e Técnica Dietética. Barueri: Manole; 2003.

27- Saglio-Yatzimirsky MC. A comida dos favelados. Estud. Av. 2006;20(58):122-132.

28- Bleil RAT. Disponibilidade de energia e nutrientes nos domicílios de famílias das regiões metropolitanas de Curitiba e Porto Alegre. [dissertação de mestrado]. Piracicaba: Escola Superior de Agricultura "Luiz de Queiroz" da USP; 2004. 87 p.

29- Faganello CRF. Disponibilidade de energia

e nutrientes para a população das regiões metropolitanas de Recife e São Paulo. [dissertação de mestrado]. Piracicaba: Escola Superior de Agricultura "Luiz de Queiroz" da USP; 2002. $113 \mathrm{p}$.

30- Menezes T, Silveira FG, Magalhães LCG, Tomich FA, Vianna SW. Gastos alimentares nas grandes regiões urbanas do Brasil: aplicações do modelo AID aos microdados da POF 1995/1996 IBGE. Brasília: IPEA; 2002. (Textos para Discussão, 896).

31- Hoffmann R. A diminuição do consumo de feijão no Brasil. Estud. Econ. 1995;25(2):189-201.

32- Silva MV. Estado nutricional de escolares matriculados nos Centros Integrados de Educação Pública - CIEP's. [tese de doutorado]. São Paulo: Faculdade de Saúde Pública da USP; 1996.110 p.

\section{Autores}

Daniela Cristina Rossetto Caroba - Doutora em Nutrição Humana Aplicada - PRONUT/USP Correspondência: Rua Regente Feijó 314 Centro - Piracicaba - SP, CEP: 13400-100 E-mail: danicaroba@hotmail.com Sonia Tucunduva Philippi - Professora Associada Faculdade de Saúde Pública/USP Marina Vieira da Silva - Professora Doutora ESALQ/USP

Recebido em: 10/10/2007

Aceito em: 28/05/2008 